Characters Useful in Determining the Position of Individual Teeth in the Permanent

Cheek-Tooth Series of Merychippine Horses

Author(s): Francis D. Bode

Source: Journal of Mammalogy, Vol. 12, No. 2 (May, 1931), pp. 118-129

Published by: American Society of Mammalogists

Stable URL: https://www.jstor.org/stable/1373910

Accessed: 08-11-2019 17:32 UTC

JSTOR is a not-for-profit service that helps scholars, researchers, and students discover, use, and build upon a wide range of content in a trusted digital archive. We use information technology and tools to increase productivity and facilitate new forms of scholarship. For more information about JSTOR, please contact support@jstor.org.

Your use of the JSTOR archive indicates your acceptance of the Terms \& Conditions of Use, available at https://about.jstor.org/terms

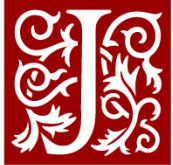

American Society of Mammalogists is collaborating with JSTOR to digitize, preserve and extend access to Journal of Mammalogy 


\section{CHARACTERS USEFUL IN DETERMINING THE POSITION OF INDIVIDUAL TEETH IN THE PERMANENT CHEEK- TOOTH SERIES OF MERYCHIPPINE HORSES}

\section{By Francis D. Bode}

\section{INTRODUCTION}

Cheek-teeth of fossil horses display structural characters which have long been recognized as of considerable value in establishing the relationships of these forms and in furnishing suggestions as to the age of the deposits in which the fossils occur. In later Cenozoic formations of western North America where complete skulls and skeletal materials are not always available, identification of members of the Equidae is often based on single teeth.

In the study of an individual hypsodont equine tooth difficulty is frequently encountered in determining with certainty its position in the cheek-tooth series. Variation in the enamel pattern as exhibited by the molars and premolars makes it particularly desirable to know where an individual tooth belongs in the series.

The problem of identifying teeth when detached from jaws arose in the study of a large number of merychippine teeth secured by the California Institute in the Merychippus Zone of the north Coalinga region, California. The collections from this Miocene horizon include approximately two thousand separate horse teeth, representing principally the species Merychippus californicus Merriam. While characters which assist in determining the position of a tooth apply particularly to this species, the criteria on which identification is made are applicable to individual teeth in a number of generic types of horses from the later Cenozoic.

The problem was suggested by Dr. Chester Stock under whose supervision it was investigated. The writer wishes to express his thanks to Dr. Stock for his kindly guidance during the course of the study. The illustrations have been prepared by Mr. John L. Ridgway.

\section{CHARACTERS AND DEFINITIONS}

The position of a tooth in the maxillary or ramus and the angle which its vertical axis makes with the plane of the occlusal surface of the series governs in large measure the attitude of the surface of wear as seen in external view. As is shown in figure 1, the plane of the occlusal surface truncates the crown of each tooth in the series at a slightly 
different angle. These angles rarely vary beyond certain characteristic limits. Consequently they furnish a reliable means by which the position of individual permanent cheek-teeth in practically all of the later Tertiary horses can be definitely established.

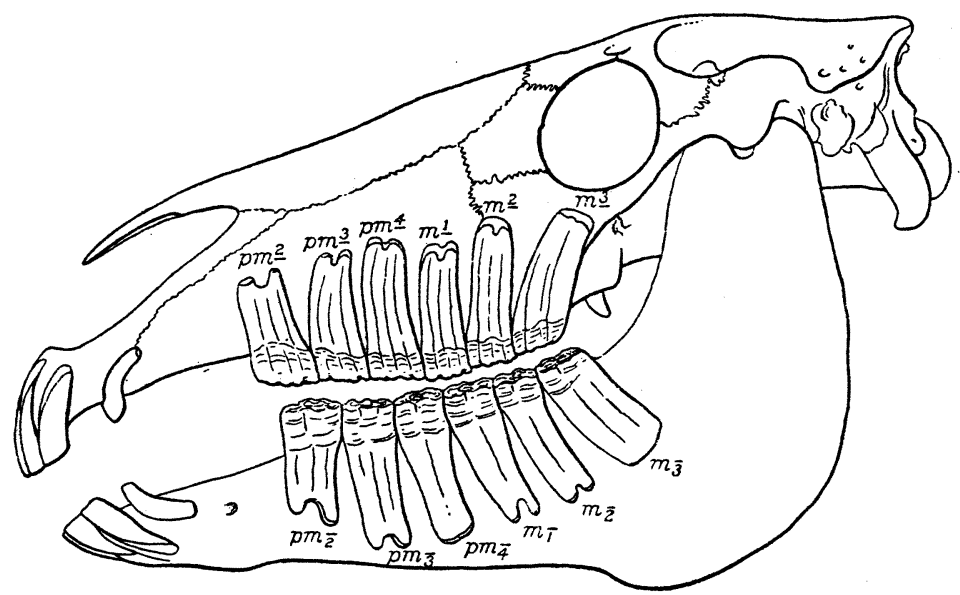

FIg. 1. Lateral view of skull and jaw of modern horse (Equus caballus Linnaeus) showing position of cheek teeth in maxillary and ramus, and characteristic angles at which plane of occlusal surface truncates crown of each tooth.

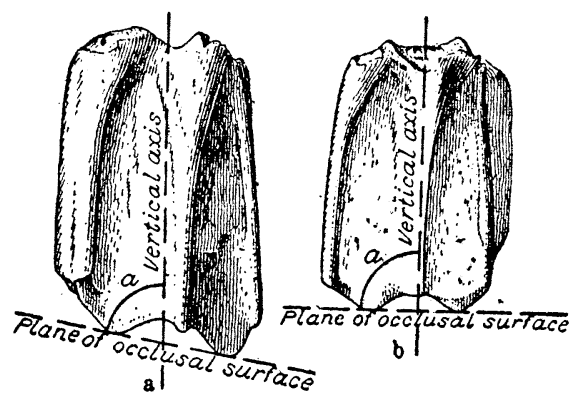

Fig. 2. Lateral views of cheek-teeth of Merychippus californicus Merriam showing position of vertical axis, plane of occlusal surface, and angle of slope (a). Fig. $2 a, \mathrm{P}^{4}$; fig. $2 b, \mathrm{M}^{1}$.

In the superior cheek-tooth series the premolars are differentiated from the molars by the relative breadth of the parastyle when compared with the mesostyle (fig. 3). The parastyle of a premolar tooth is noticeably broader than the mesostyle. In a molar tooth these two styles are 
subequal in size. This character is of general application. A broad parastyle is indicative of a premolar tooth in practically all of the genera of horses with hypsodont teeth.

The vertical axis of the crown is an imaginary line passing through the center of the occlusal surface and the center of the base of the crown (fig. 2). The slope of the occlusal surface refers to the downward slant of this surface, in either direction, when the tooth is held in a vertical position. A superior cheek-tooth is held with its occlusal surface
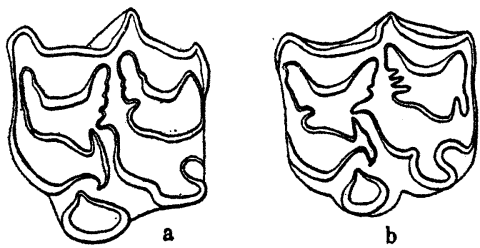

Fig. 3. Occlusal views of superior premolars of Merychippus californicus Merriam showing breadth of parastyle when compared to mesostyle. Fig. $3 a$, $\mathrm{P}^{3}$; fig. $3 b, \mathrm{P}^{4}$.
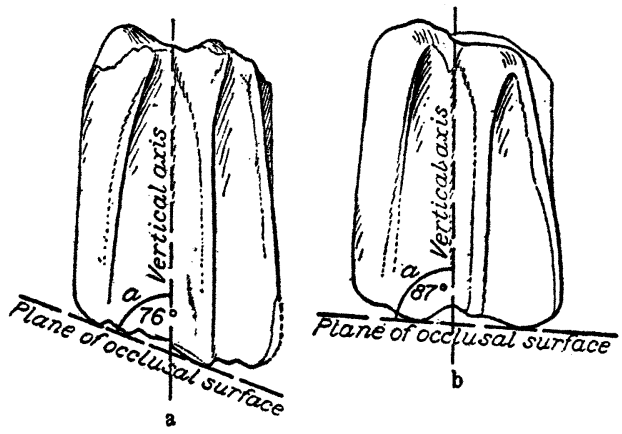

Frg. 4. Lateral views of superior premolars of Merychippus californicus Merriam showing difference in angle of slope in $\mathrm{P}^{3}$ (fig. 4a) and $\mathrm{P}^{4}$ (fig. $4 b$ ).

facing downward, and an inferior tooth with its occlusal surface facing upward. The angle of slope of the occlusal surface is the anterior angle between the occlusal surface and the vertical axis of the crown (fig. 2). The angle of slope can not be determined in an unworn tooth.

The anteroposterior-transverse ratio is obtained by dividing the anteroposterior diameter of the occlusal surface by the transverse diameter. 


\section{SYSTEM OF MEASUREMENTS}

All measurements are made exclusive of cement. Whenever possible the system of measurements suggested by J. C. Merriam ${ }^{1}$ is used. In both the upper and lower cheek-teeth the angle of slope is measured by a goniometer so constructed that the base of the instrument can rest upon the entire occlusal surface. The anterior angle between the plane of the occlusal surface and a vertical line along the center of the external side of the tooth is the angle of slope (fig. 2). This vertical line corresponds to the external projection of the vertical axis and does

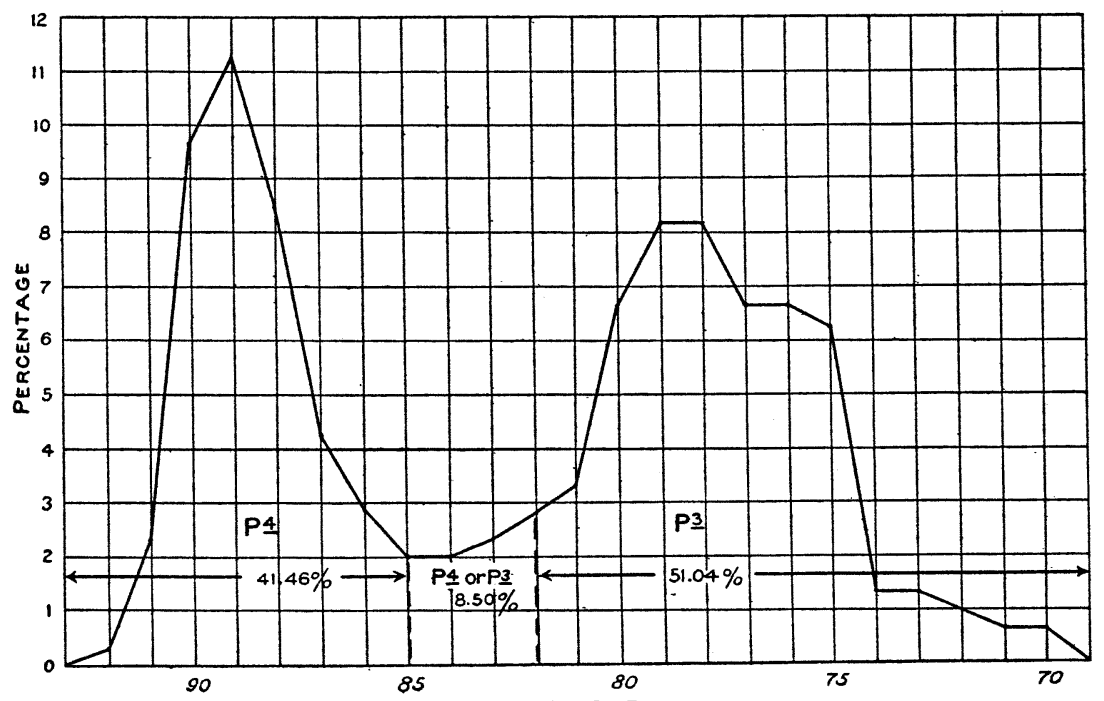

Fig. 5. Graphic representation of the frequency of occurrence of specific angles of slope in $\mathrm{P}^{3}$ and $\mathrm{P}^{4}$.

not usually coincide with the column of the mesostyle. Erroneous values are almost certain to be obtained if the attitude of this column influences the measurements.

In superior cheek-teeth the anteroposterior diameter is the distance across the occlusal surface from the middle of the faces of contact of the adjoining anterior and posterior teeth. This diameter does not include the anterior projection of the parastyle in advance of the principal contact plane of the tooth. The anteroposterior diameter in the

${ }^{1}$ Univ. Calif. Pub., Bull. Dept. Geol., vol. 7, no. 21, p. 409, 1913. 
inferior cheek-teeth is measured from the middle of the contact plane of the anterior wall of the crown to the extreme posterior projection of the entostylid.

The transverse diameter of the upper cheek-teeth is measured from the deepest indentation of the paracone wall to the farthest lingual projection of the protocone. In the inferior series the transverse diameter is the greatest distance measured between the protoconid and the metaconid. With an unworn tooth the measurements are taken one-third of the distance from the summit to the base of the crown. When the enamel is covered with cement the diameters can not be ac-
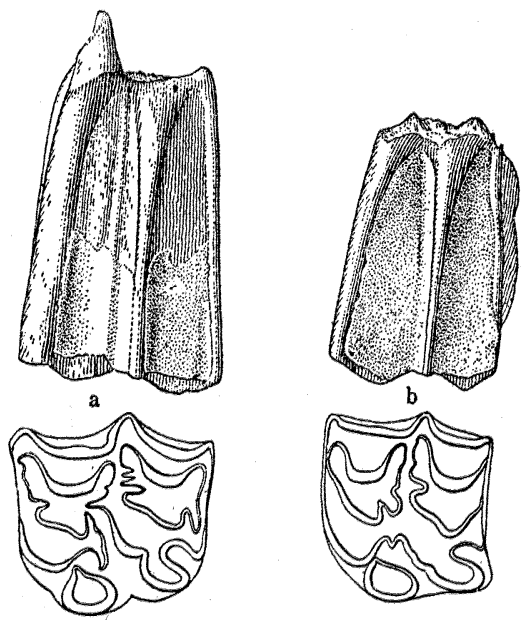

Fig. 6. Lateral and occlusal views of $\mathrm{P}^{4}$ (fig. 6a) and $\mathrm{M}^{1}$ (fig. $6 b$ ) of Merychippus californicus Merriam showing difference in breadth of parastyle.

curately measured. The data for each of these frequency curves were obtained from more than 200 teeth.

\section{SUPERIOR CHEEK-TEETH}

The outstanding characters exhibited by $\mathrm{P}^{2}$ and $\mathrm{M}^{3}$ afford a ready identification of these teeth. The great enlargement of the parastyle and the pointed anterior wall of the crown of the tooth distinguish $\mathrm{P}^{2}$ from all other teeth in the superior dentition. Likewise in $\mathrm{M}^{3}$ the extreme backward curvature of the vertical axis from the plane of the occlusal surface, the indentation of the posterior wall, and the absence of a surface of attrition caused by wear of a more posterior tooth, permit an identification of the last molar without much difficulty. 
The broad parastyle of the premolars, figure 3, furnishes a distinguishing feature for these teeth. ${ }^{2}$ The distinctive breadth of the parastyle is shown not only on the occlusal surface but also on the outer side by the broadness of this style when compared to the column of the mesostyle. The angle of slope of the occlusal surface serves to separate $\mathrm{P}^{3}$ from $\mathrm{P}^{4}$ but is not of value in distinguishing $\mathrm{P}^{4}$ from $\mathrm{M}^{1}$. This angle varies from $92^{\circ}$ to approximately $70^{\circ}$ in premolar teeth. The third

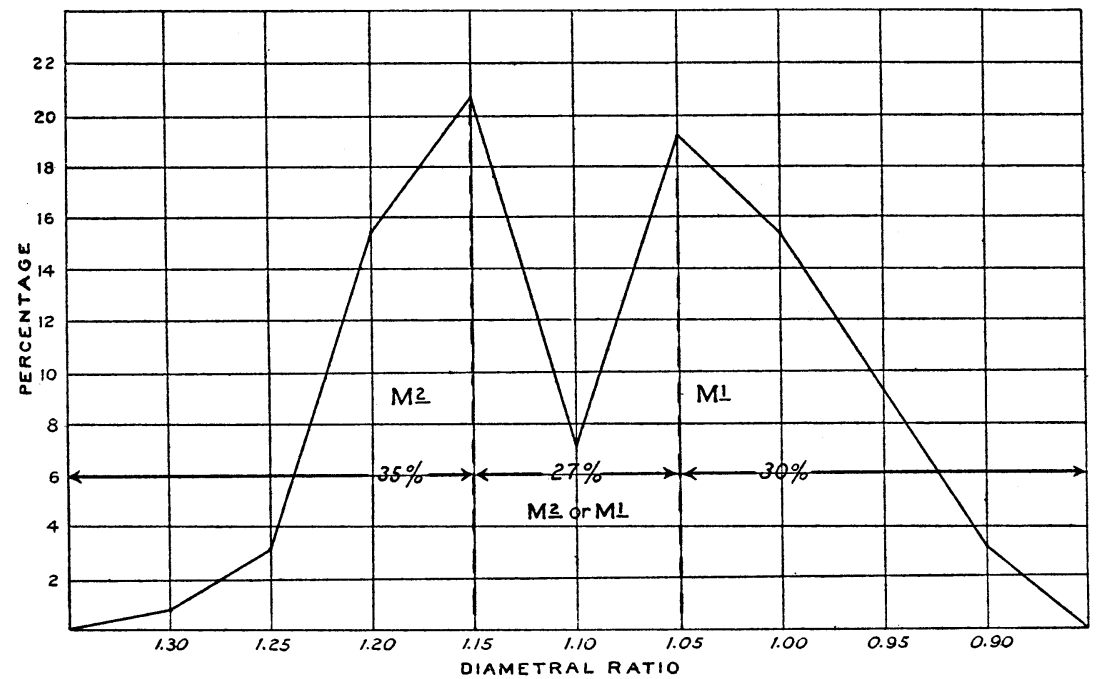

FIG. 7. Graphic representation of the frequency of occurrence of specific values of the anteroposterior-transverse ratio in $\mathbf{M}^{1}$ and $\mathbf{M}^{2}$.

premolar is characterized by an angle of slope of $82^{\circ}$ or less. This angle has a range from $92^{\circ}$ to $85^{\circ}$ in fourth premolars. A tooth whose angle of slope lies between $85^{\circ}$ and $82^{\circ}$ can not be definitely placed in its correct position in the premolar series although it is probable that

${ }^{2}$ In the upper premolars the mesostyle also is usually more prominent than in the molars, especially in Equus and genera of the late Tertiary.

Difference in the position of the adjacent horns of the cement lakes, as observed in the molars and premolars, is also an aid in determining the allocation of isolated teeth in horses. In the molars the horns of these cement lakes are usually subequal. In the premolars the anterior horn of the posterior lake extends outward and forward well beyond the posterior horn of the anterior lake.

Still another determining factor is the fact that, in general, the upper premolars of horses have a relatively greater antero-posterior diameter than molars belonging in the same cheek tooth series.-J. W. Gidley. 
it belongs to the fourth premolar position. The difference in slope is well illustrated by figure 4 . Figure $4 a$ shows a third premolar with an angle of slope of $76^{\circ}$, while the $87^{\circ}$ angle shown in figure $4 b$ is characteristic of the fourth premolar position. The differences can usually be recognized without the use of a goniometer. A graphical representation of the frequency of occurrence of specific angles of slope is shown in figure 5. The angles have been plotted on the abscissae and the percentages of teeth possessing a given angle are recorded on the ordinates. The presence of two well defined maxima on this curve demonstrates the practicability of this method of distinguishing $\mathrm{P}^{3}$ from $\mathrm{P}^{4}$.

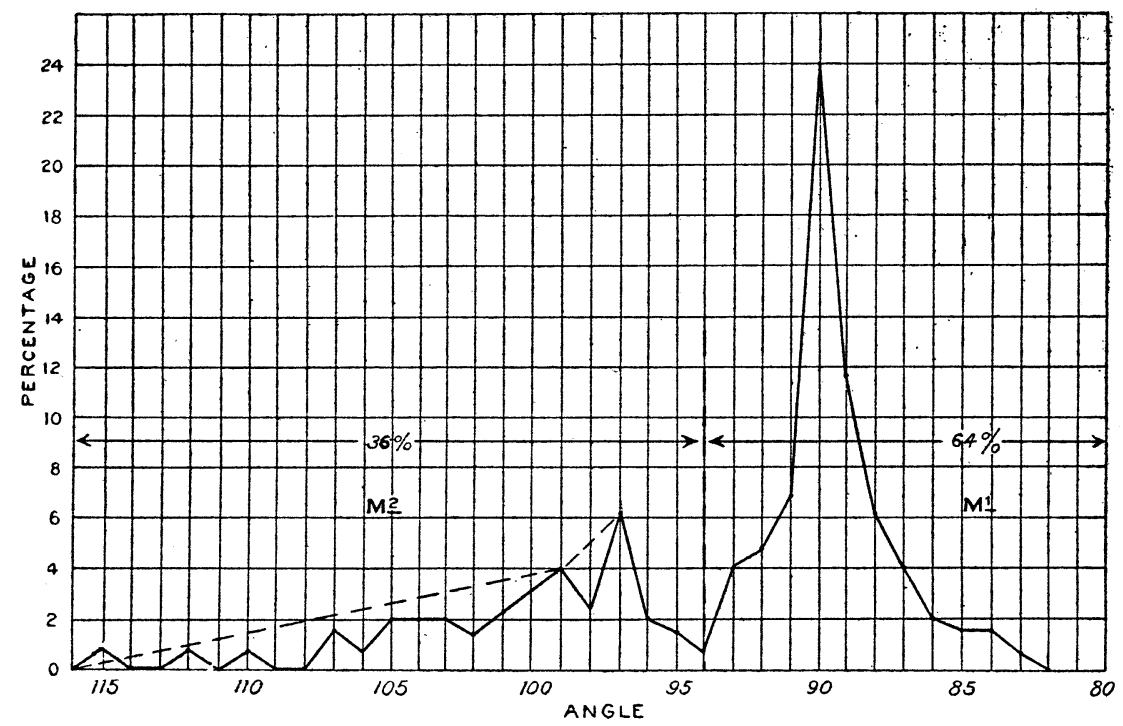

FIG. 8. Graphic representation of the frequency of occurrence of specific angles of slope in $\mathbf{M}^{1}$ and $\mathbf{M}^{2}$.

$\mathrm{M}^{1}$ and $\mathrm{M}^{2}$, though readily distinguished by their slenderness of parastyle from the premolars (figure 6), are sometimes difficult to set apart. Two characters, namely the anteroposterior-transverse ratio and the angle of slope of the occlusal surface are frequently diagnostic. The ratio of the anteroposterior and transverse diameters is not always a satisfactory character because this ratio approaches the same value for all molar teeth after more than one-half of the height of the crown has been removed by wear. However, if not more than one-third of the crown has been worn away this ratio may be used to advantage. 
Figure 7 is a graphic representation of the frequency of occurrence of specific values of the anteroposterior-transverse ratio in $\mathbf{M}^{1}$ and $\mathbf{M}^{2}$.

In plotting a curve, figure 8 , showing the frequency of occurrence of specific angles of slope in $\mathrm{M}^{1}$ and $\mathrm{M}^{2}$ two maxima were obtained. According to the measurements the teeth fall into two groups, one of which (64 per cent) is distinctly larger than the other (36 per cent). Apparently some second molars have an angle of slope which approximates $90^{\circ}$. When, however, the angle between the plane of the occlusal surface and the vertical axis deviates in individual teeth from a right angle it is usually greater than $95^{\circ}$.
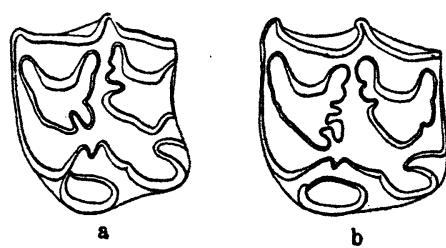

Fig. 9. Occlusal view of $\mathrm{M}^{1}$ (fig. $9 a$ ) and $\mathrm{M}^{2}$ (fig. $9 b$ ) of Merychippus californicus Merriam showing difference in anteroposterior diameters when compared to transverse diameters.
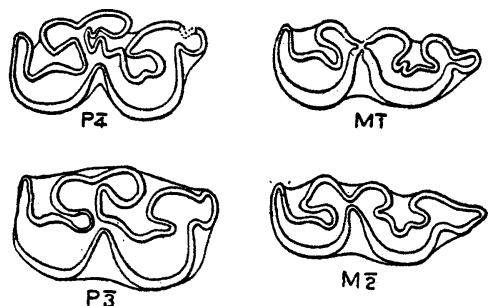

Fig. 10. Occlusal view of $\mathbf{P}_{3}, \mathbf{P}_{4}, \mathbf{M}_{1}$, and $\mathbf{M}_{2}$ of Merychippus californicus Merriam showing anteroposterior compression of enamel pattern in premolars, and characteristic posterior projection of entostylid in molars.

In $\mathrm{M}^{1}$ the anteroposterior and transverse diameters of the occlusal surface, figure $9 a$, are subequal and the diametral ratio has a value of 1.05 or less. The angle of slope of the occlusal surface approaches $90^{\circ}$. An angle of slope of less than $90^{\circ}\left(89^{\circ}\right.$ to $\left.85^{\circ}\right)$ is always indicative of the first molar position. The occurrence of an angle of $90^{\circ}$ is much more frequent in $\mathrm{M}^{1}$ than in $\mathrm{M}^{2}$.

The occlusal surface of $\mathrm{M}^{2}$ tends to be elongate in an anteroposterior direction (fig. 9b). The anteroposterior-transverse ratio has a value of 1.15 or greater. A value of 1.20 or more is probably always indicative 
of the second molar position. If a tooth belonging to the first or second molar position possesses an angle of slope greater than $95^{\circ}$ it can be definitely ascribed to $\mathrm{M}^{2}$.

A molar tooth more than one-third worn, with an anteroposteriortransverse ratio less than 1.15 , and an angle of slope between $90^{\circ}$ and $95^{\circ}$, can not be definitely placed in the series.

\section{INFERIOR CHEEK-TEETH}

As in the superior cheek-tooth series, $\mathrm{P}_{2}$ and $\mathrm{M}_{3}$ can be readily identified. The great enlargement of the parastylid and the pointed anterior

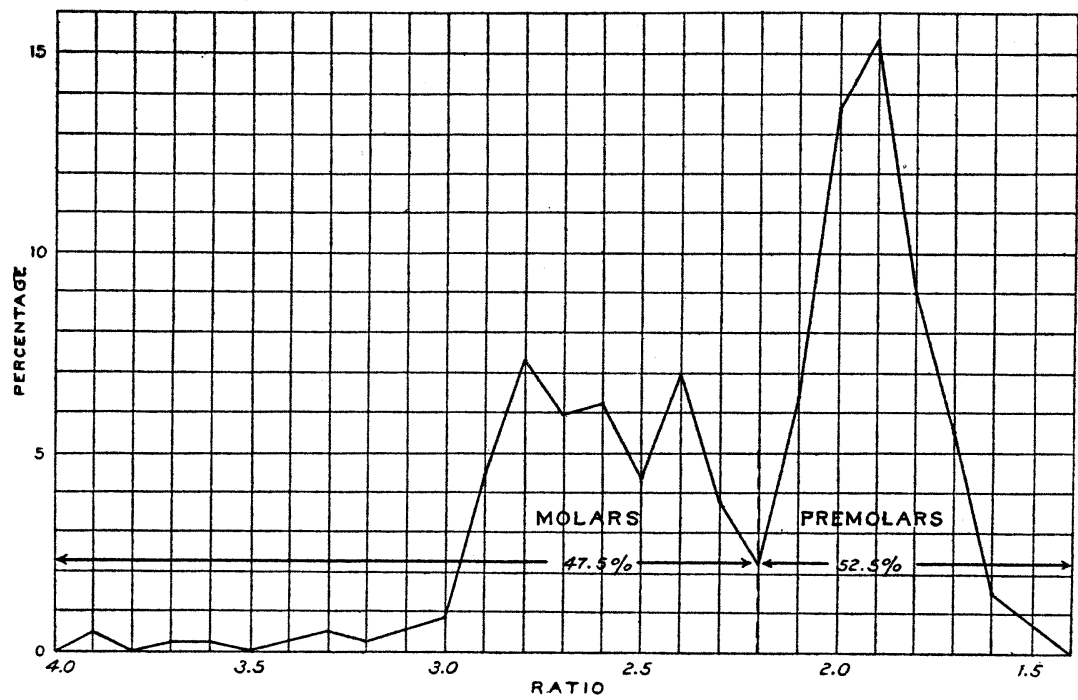

FIG. 11. Graphic representation of the frequency of occurrence of specific values of the anteroposterior-transverse ratio in inferior premolars and molars.

wall of the crown as viewed in cross-section are characters peculiar to $P_{2}$ alone. In $M_{3}$ the extreme backward curvature of the vertical axis from the plane of the occlusal surface, the presence of an entostylid column with anteroposterior diameter approximately equal to that of the protoconid or hypoconid, and the absence of a surface of attrition caused by wear of a more posterior tooth, distinguish this molar from all other teeth in the inferior dentition.

In merychippine forms the inferior premolars are distinguished from the molars by their more massive appearance (fig. 10). Moreover, the 
enamel pattern of a premolar tooth exhibits a compression in an anteroposterior direction. The entostylid in premolar teeth is flattened against the posterior side of the entoconid and never shows the extreme pos-
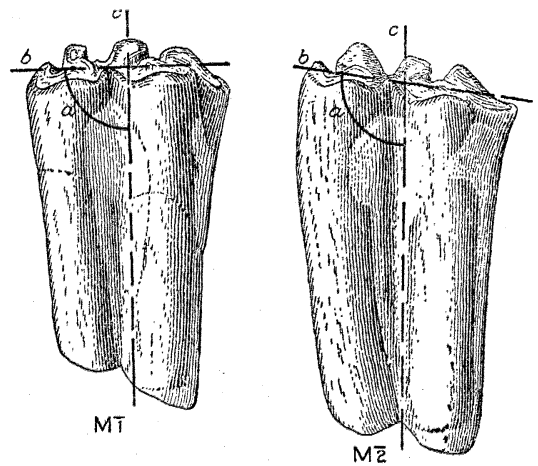

Fig. 12. Lateral view of inferior molars in Merychippus californicus Merriam showing differences in the angle of slope (a) in $M_{1}$ and $M_{2}$, vertical axis (c), and plane of the occlusal surface (b).

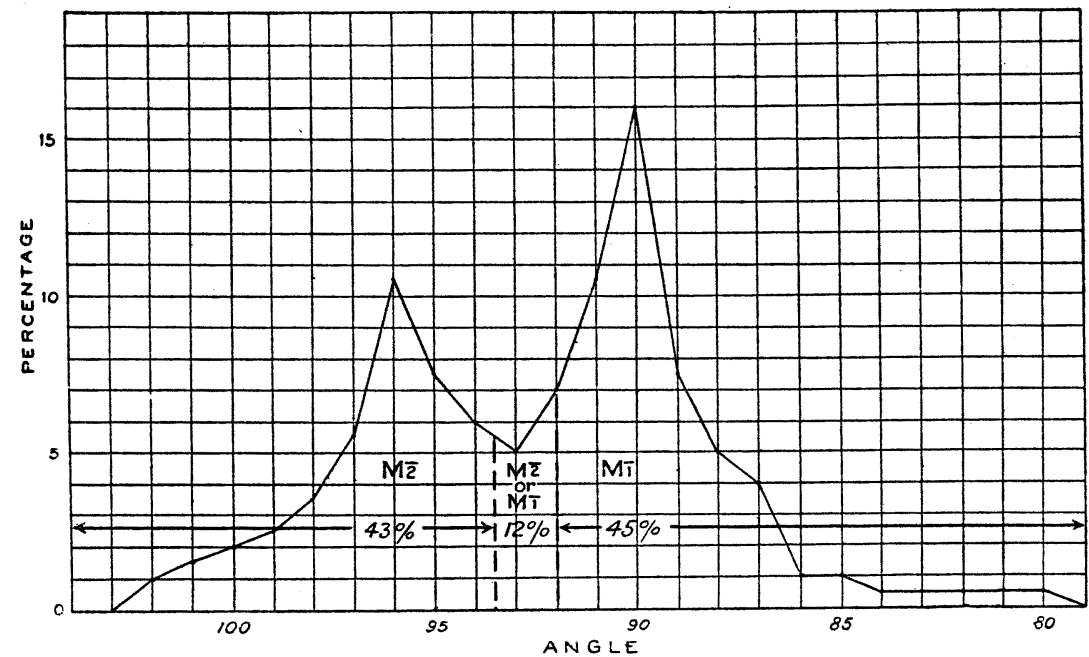

FIG. 13. Graphic representation of the frequency of occurrence of specific angles of slope in $\mathbf{M}_{1}$ and $\mathbf{M}_{2}$.

terior projection seen in the molars (fig. 10). The significance of this compression in distinguishing premolars from molars is graphically expressed when the anteroposterior-transverse ratio is plotted (fig. 11). 
The premolars have an anteroposterior-transverse ratio that varies between the limits 2.1 and approximately 1.5 , while in the molars this ratio ranges from 2.3 to approximately 4.0. While a value of 2.3 or more is always indicative of a molar tooth, the ratio in molars varies with the degree of wear of the crown. A first or second molar that has had more than two-thirds of its crown removed by wear frequently has an anteroposterior-transverse ratio less than 2.1, and is therefore difficult to distinguish from a worn premolar.

In the entire collection of merychippine teeth from the Coalinga locality the greatest difficulty is experienced in attempting to distinguish $\mathrm{P}_{3}$ from $\mathrm{P}_{4}$. The occurrence of angles of slope of less than $90^{\circ}$ is probably more frequent in third premolars than in fourth premolars, but not to the extent needed in furnishing a definite clue as to identity. It is doubtful whether the characters which have been employed in establishing the identity of individual teeth are applicable to the third and fourth premolars. In this connection it should be noted that the great similarity which fortunately prevails between these teeth lessens somewhat the necessity of discriminating between the two positions.

The angle of slope of the occlusal surface serves to identify $M_{1}$ and $\mathbf{M}_{2}$ (fig. 12). The curve showing the percentage of occurrence of the different angles in these teeth, figure 13, has two distinct maxima, one at $90^{\circ}$ and the other at $96^{\circ}$. If the occlusal surface has an angle of slope of $91^{\circ}$ or less the tooth may be assigned to the first molar position. Likewise an angle of slope of $95^{\circ}$ or greater is indicative of the second molar position. A tooth in which the angle has a value lying between $94^{\circ}$ and $91^{\circ}$ can not be definitely determined as to position.

Summary of characters useful in determining the position of individual teeth Superior cheek-teeth

\begin{tabular}{|c|c|c|c|}
\hline тоотн & PARASTYLE & ANGLE OF SLOPE & $\begin{array}{l}\text { ANTEROPOSTERIOR- } \\
\text { TRANSVERSE RATIO }\end{array}$ \\
\hline P2 & \multicolumn{2}{|c|}{$\begin{array}{l}\text { Parastyle greatly enlarged } \\
\text { Crown wedge-shaped with apex anterior }\end{array}$} & \\
\hline P3 & Broad & $82^{\circ}$ or less & \\
\hline $\mathrm{P} 4$ & Broad & $85^{\circ}$ to $92^{\circ}$ & \\
\hline M1 & Slender & $85^{\circ}$ to $91^{\circ}$ & 1.05 or less \\
\hline M2 & Slender & $94^{\circ}$ or greater & 1.15 or greater \\
\hline M3 & \multicolumn{2}{|c|}{$\begin{array}{l}\text { Posterior wall of crown deeply indented } \\
\text { Absence of surface of attrition on posterior wall }\end{array}$} & r wall \\
\hline
\end{tabular}


Inferior cheek-teeth

\begin{tabular}{|c|c|c|c|}
\hline тоотн & ANGLE OF SLOPE & $\begin{array}{l}\text { ANTEROPOSTERIOR- } \\
\text { TRANSVERSE RATIO }\end{array}$ & ENTOBTYLID \\
\hline P2 & \multicolumn{2}{|c|}{$\begin{array}{l}\text { Parastylid greatly enlarged } \\
\text { Crown wedge-shaped with apex anterior }\end{array}$} & \\
\hline P3 & $93^{\circ}$ or less & Less than 2.1 & Compressed \\
\hline P4 & $85^{\circ}$ or $93^{\circ}$ & Less than 2.1 & Compressed \\
\hline M1 & $91^{\circ}$ or less & Greater than 2.3 & $\begin{array}{l}\text { Posterior projection } \\
\text { marked }\end{array}$ \\
\hline M2 & $94^{\circ}$ or greater & Greater than 2.3 & $\begin{array}{l}\text { Posterior projection } \\
\text { marked }\end{array}$ \\
\hline M3 & \multicolumn{3}{|c|}{$\begin{array}{l}\text { Entostylid column as large as protoconid and hypoconid } \\
\text { Crown with extreme backward curvature } \\
\text { Absence of surface of attrition on posterior wall }\end{array}$} \\
\hline
\end{tabular}

California Institute of Technology, Pasadena, California.

\section{THE BREEDING SEASON IN MONKEYS, WITH SPECIAL REFERENCE TO PITHECUS (MACACUS) RHESUS}

\section{By Carl G. Hartman}

The intensive study of the sexual cycle in the rhesus females of the Carnegie Colony soon gave the very definite impression that the summer months constitute the non-breeding season, when the ovulatory function is at a low ebb and the menstrual cycle as well as the behavior of the sexes to each other show more aberrant phenomena than during the more favorable, the colder, months of the year. The impression has become a certainty. It is the purpose of the present paper to present the evidence along several lines, all of which point in the same direction.

\section{THE IMPRESSIONS OF TRAVELERS}

The general testimony in the literature is to the effect that monkeys do not have a breeding season. This is based upon the casual observation of travelers and hunters who enter a country or province during a season favorable to their purposes and, seeing young of various ages, conclude that a given species of monkey breeds all the year round. I find this statement in books, I have it in my correspondence, it is communicated to me personally. Even Sányal, the efficient director of the Calcutta Zoological Garden, was misled in this way (cf. Heape; 